\title{
Disc herniation or ependymoma recurrence?
}

\author{
Aristeidis H. Katsanos ${ }^{1}$, loannis Sarmas ${ }^{1}$, Sotirios Giannopoulos ${ }^{1,2}$, Sigliti-Henrietta Pelidou ${ }^{1,2}$, Athanassios P. \\ Kyritsis ${ }^{1,2}$ \\ ${ }^{1}$ Department of Neurology, School of Medicine, University of Ioannina, 45110 Ioannina, Greece. \\ ${ }^{2}$ Neurosurgical Intitute, School of Medicine, University of Ioannina, 45110 Ioannina, Greece.
}

\section{A B S T RA C T}

In this paper, a 41-year-old female with previous history of ependymoma is reported. The patient underwent gross-total resection of the tumor and ventriculo-peritoneal shunt placement, followed by radiotherapy to the posterior fossa and the upper-cervical spinal cord region. Three years later she developed numbness in her right arm, body and leg. Magnetic resonance imaging (MRI) of the entire neuraxis revealed no evidence of tumor recurrence, while a small enhancing area was noted in the left anterolateral spinal cord at the level of the C1-C2 vertebrae and a left posterior-lateral herniated disk in the C5-C6 level which was not present in the earlier MRI at initial diagnosis. Lumbar punctures were negative for malignant cells. The patient's symptoms were first attributed to radiation-induced effect. Follow-up results of brain and the cervical spine MRI were performed which showed disappearance of the small abnormality in the left C2 spinal cord area but persistence of the herniated C5-C6 disk. Thus, the current diagnosis of right-sided numbness due to pressure of the left anterolateral spinothalamic tracts from the herniated C5-C6 disk was made. This is a unique case, in which herniated disk pressuring effects needed to be differentiated from both radiation-induced treatment effect and tumor recurrence.

Key words: Disc herniation; ependymoma recurrence; radiotherapy

\section{INTRODUCTION}

Most of the intracranial ependymomas in adults are supratentorial in contrast to the childhood ependymomas that are usually infratentorial..1] According to the World Health Organization (WHO) they are classified into grades I, II and III. ${ }^{[2]}$ Grade I includes the myxopapillary ependymoma and subependymoma; grade II is the most common variant and grade III is the anaplastic variant. Gross total resection followed by limited-field radiotherapy is the standard form of treatment in uncomplicated cases. ${ }^{[3,4]}$ Craniospinal radiation should be reserved only for cases where there is documented leptomeningeal seeding. ${ }^{[1,5]}$ Radiation necrosis is a rare complication $(<5 \%)$ of conventional radiotherapy, ${ }^{[6]}$ but when it does occur it poses a challenge to differentiate from tumor recurrence..$^{[7,8]}$ We report herein a unique case where a herniated disk in a patient with a previously

\section{Corresponding Author: Dr. Aristeidis H. Katsanos,}

Department of Neurology, School of Medicine, University of loannina, Stavros Niarchos Avenue, 45110 loannina, Greece. E-mail: ar.katsanos@gmail.com

\begin{tabular}{|l|l|}
\hline \multicolumn{2}{|c|}{ Access this article online } \\
\hline Quick Response Code: & Website: \\
\hline & www.nnjournal.net \\
\cline { 2 - 2 } & \\
& \\
\end{tabular}

treated ependymoma needed to be differentiated from radiation-induced injury and tumor recurrence.

\section{CASE REPORT}

ependymoma presented to the Neurology clinic for persisted numbness in her right arm, body and leg of 10-month duration. The patient was diagnosed 3 years earlier with hydrocephalus due to a fourth ventricular ependymoma, without evidence of cerebrospinal fluid (CSF) seeding in magnetic resonance imaging (MRI) of the brain or the entire spine [Figure 1]. At that time, she underwent gross-total resection of the tumor and ventriculo-peritoneal shunt placement, followed by 6,000 rads radiotherapy to the posterior fossa and the upper-cervical spinal cord region. Approximately 10 months prior to her visit to our clinic, the patient developed unilateral numbness in her right arm, body and leg, worse in the leg than in the arm. MRI of the entire neuraxis revealed no evidence of tumor recurrence. However, a small enhancing area

This is an open access article distributed under the terms of the Creative Commons Attribution-NonCommercial-ShareAlike 3.0 License, which allows others to remix, tweak, and build upon the work non-commercially, as long as the author is credited and the new creations are licensed under the identical terms.

For reprints contact: service@oaepublish.com

Cite this article as: Katsanos AH, Sarmas I, Giannopoulos S, Pelidou SH, Kyritsis AP. Disc herniation or ependymoma recurrence? Neuroimmunol Neuroinflammation 2016;3:65-8.

Received: 30-09-2015; Accepted: 05-01-2016 
was noted in the left anterolateral spinal cord at the level of the C1-C2 vertebrae [Figures 2 and 3]. A left anterior-lateral herniated disk was also noted in the C5-C6 level which was not present in the initial MRI at diagnosis [Figures 2 and 4]. Three lumbar punctures were negative for malignant cells. The possibility of ependymoma recurrence was therefore ruled out and the symptoms were attributed to radiation-induced effect. The patient continued to be followed with frequent MRI. Although the followingup MRI demonstrated progressive reduction of the enhancing abnormality in the upper cervical cord, the patient's symptoms persisted and she presented to our clinic for a second opinion. The neurological examination was unremarkable except for decreased pinprick and temperature sensation in her right side below the C5 dermatome. Additional MRI of the brain (not shown) and the cervical spine were performed which revealed disappearance of the previously noted small abnormality in the left C2 spinal cord area but persistence of the herniated C5-C6 disk [Figures 5 and 6]. The diagnosis of right-sided numbness due to selective

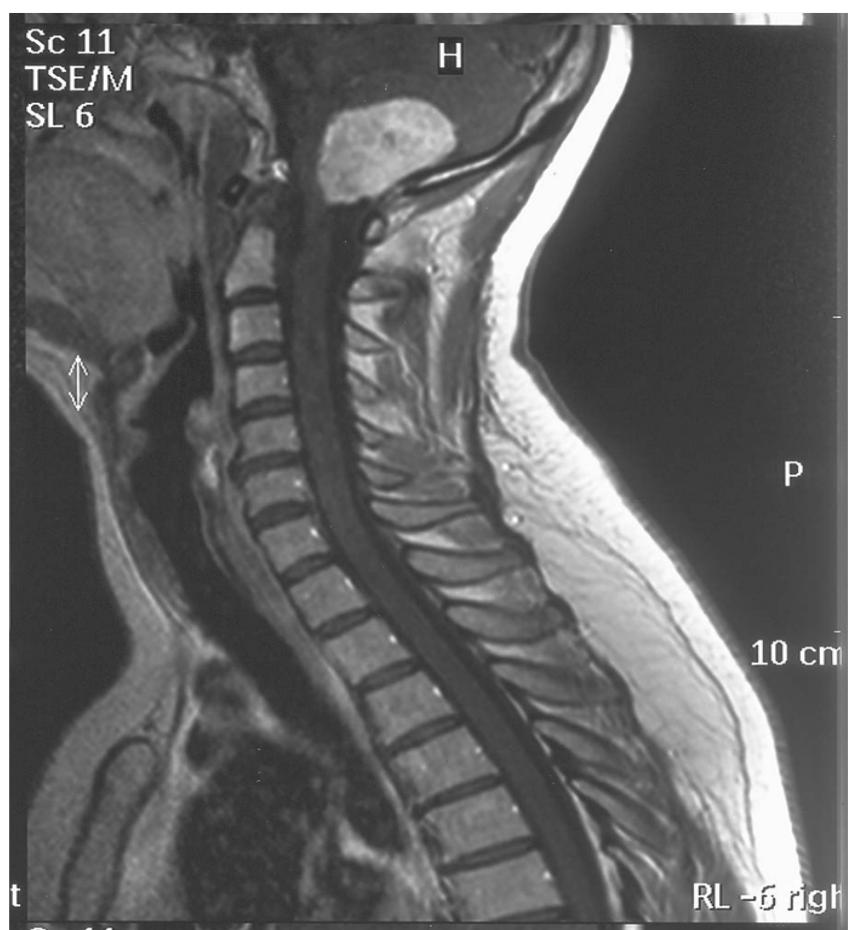

Figure 1: Pre-surgical T1-weigheted sagittal MRI with contrast of the C-spine. The large homogenously enhancing tumor of the posterior fossa is seen but no evidence of leptomeningeal disease or herniated disk at the C5-C6 level. MRI: magnetic resonance imaging

pressure of the left anterolateral spinothalamic tracts by the herniated C5-C6 disk was therefore made.

\section{DISCUSSION}

Ependymomas in adults are more frequently supratentorial (approximately $2 / 3$ of cases) in contrast to children that are infratentorial. ${ }^{[1]}$ When they are located in the posterior fossa, they can fill the fourth

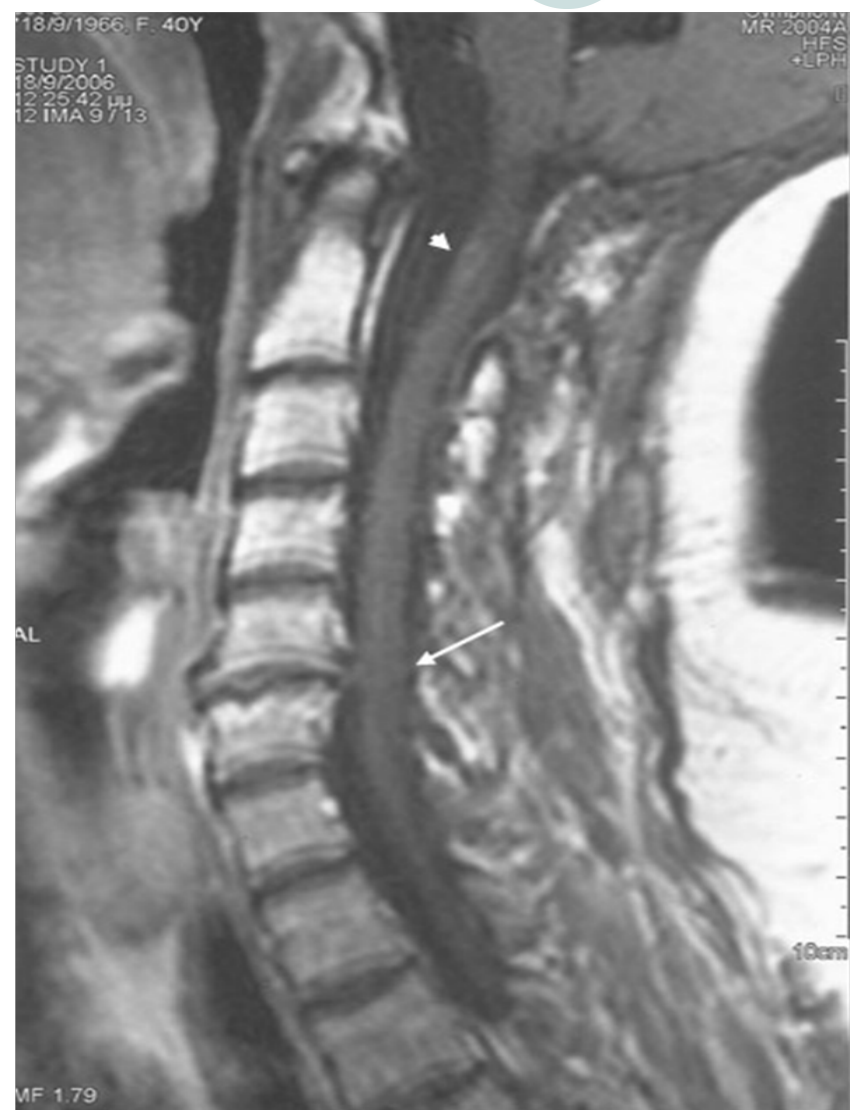

Figure 2: T1-weigheted MRI with contrast of the C-spine when the patient developed right-sided numbness. There is no evidence of tumor recurrence in the posterior fossa but there is an enhancing spinal cord abnormality at the C2 level (arrowhead), and a herniated disk at the C5-C6 level (arrow). MRI: magnetic resonance imaging

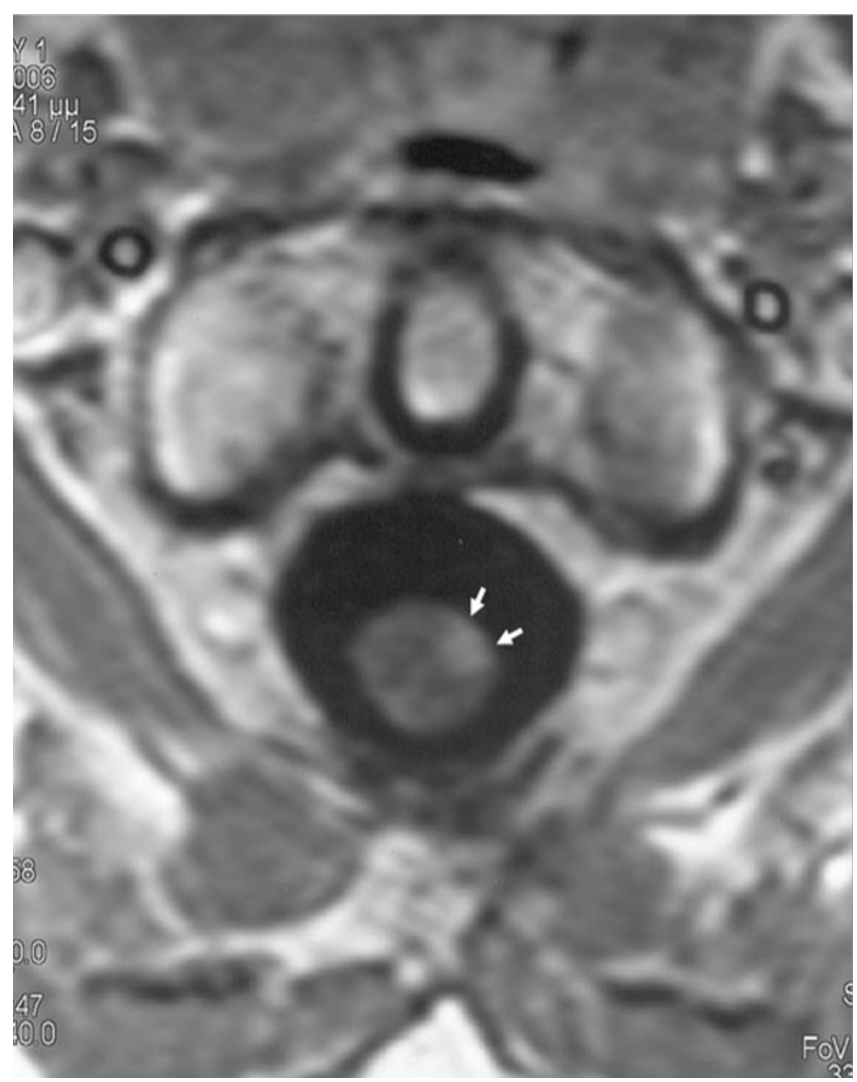

Figure 3: Transverse T1-weigheted MRI section with contrast through the C2 area revealed the small cord abnormality to be located in the left anterolateral region without mass effect, consisted with radiation damage. MRI: magnetic resonance imaging 


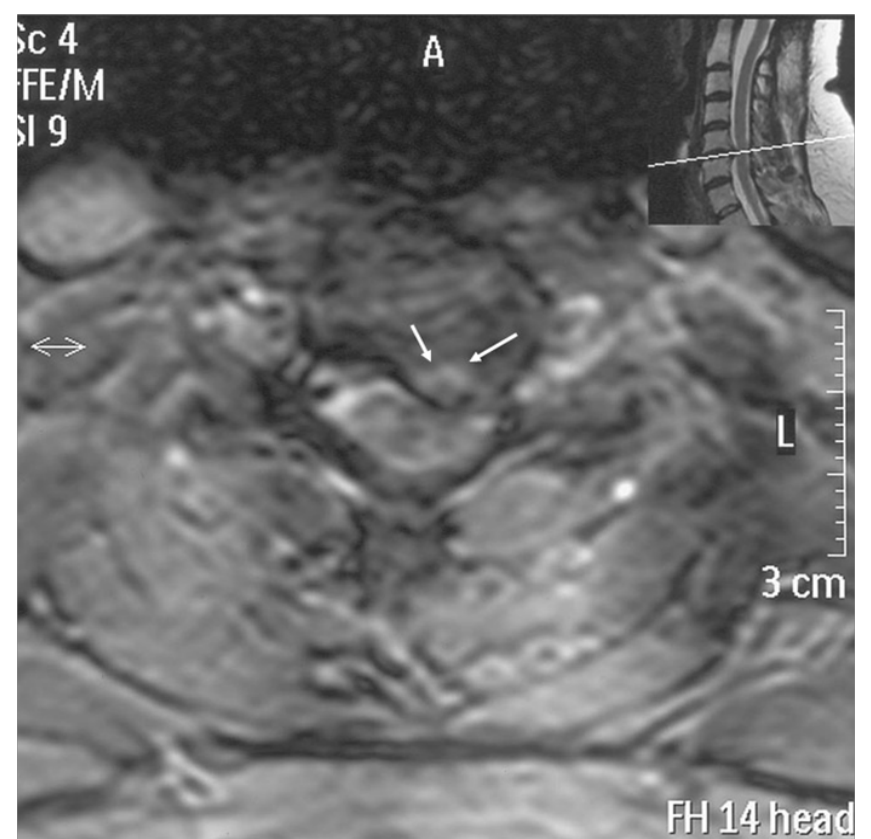

Figure 4: Transverse T2-weigheted MRI section through the C5-C6 area revealed the herniated disk fragment to compress the left anterolateral spinal cord. MRI: magnetic resonance imaging

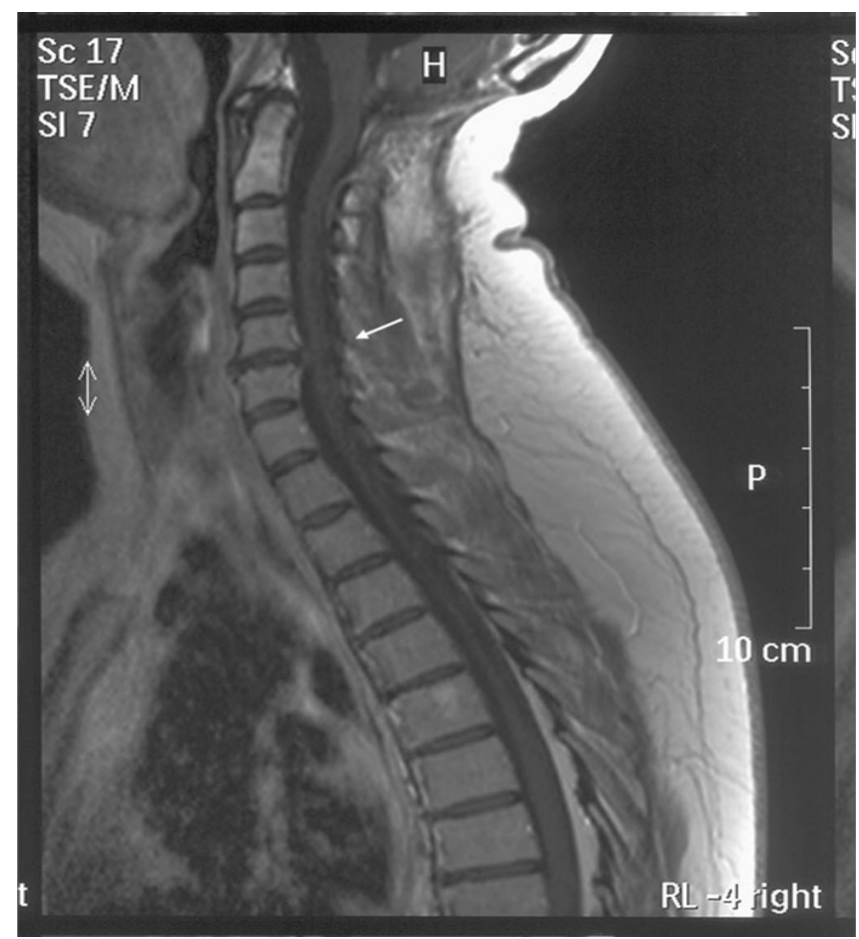

Figure 5: T1-weigheted MRI with contrast of the C-spine during the patient's visit to our clinic demonstrating disappearance of the $\mathrm{C} 2$ spinal cord lesion but presence of the herniated disk at the C5-C6 level (arrow). MRI: magnetic resonance imaging

ventricle and cause hydrocephalus, as in our case. Gross-total resection followed by local radiotherapy could be curative if there is no CSF seeding. ${ }^{[3-5]}$ During tumor recurrence, local recurrence is the primary pattern of failure and spinal seeding is uncommon in the absence of local failure. ${ }^{[1]}$ In the present case, a herniated C5-C6 disk compressed only the left anterolateral spinothalamic tracts but not the left C6 nerve root or the corticospinal tracts, resulted in controlateral arm, body and leg sensory changes. This

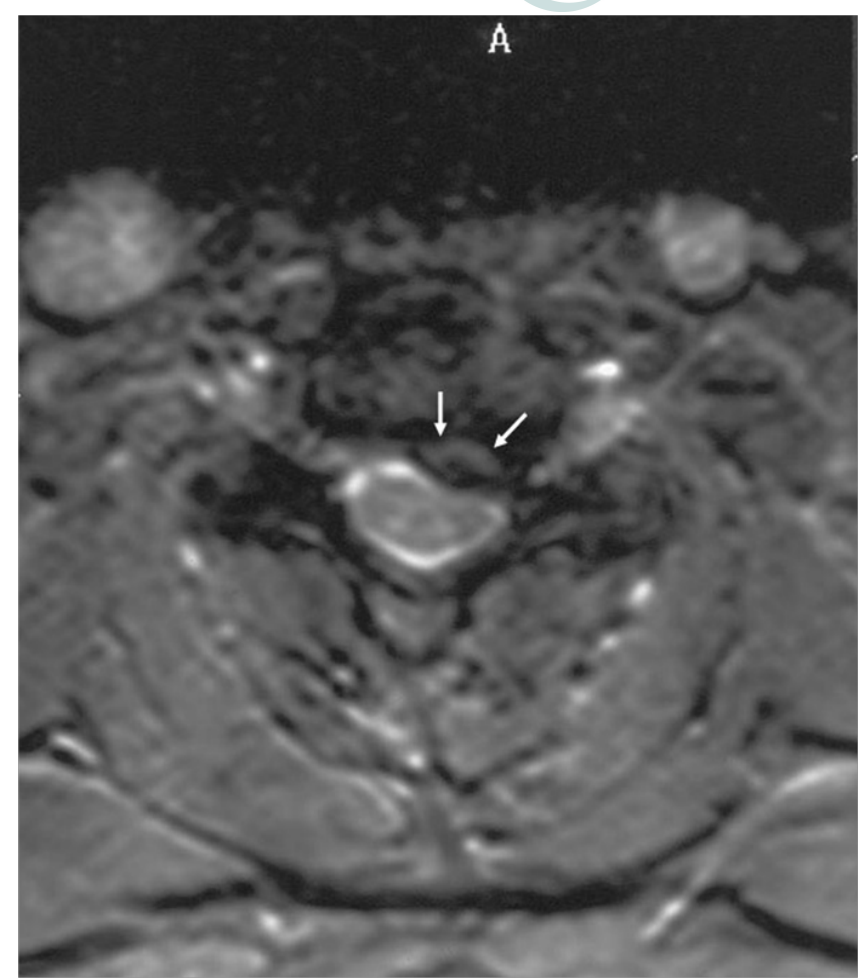

Figure 6: Transverse T2-weigheted MRI section through the C5-C6 area showing unchanged the herniated disk fragment compressing the left anterolateral spinal cord (arrows). MRI: magnetic resonance imaging

is an unusual case since one would expect symptoms primarily related to the nerve root compression in addition to the spinal cord impingement. Furthermore, even in anterolateral disk herniation, the spinal cord was compressed, and corticospinal tract signs should be expected besides the spinothalamic tract signs.

In conclusion, this represents a unique case in which a herniated disk presses only the spinothalamic tracts, and that needed to be differentiated from a temporarily occurred asymptomatic radiation-induced effect, and tumor recurrence. The patient was instructed to wear a soft collar and avoid heavy use of her arms. The patient also received medical treatment with nonsteroidal antiinflammatory drugs and gabapentin. Laminectomy was not performed due to the significant clinical improvement after the medical therapy, while the patient has improved at the 6-month follow-up evaluation.

\section{Financial support and sponsorship}

Nil.

\section{Conflicts of interest}

There are no conflicts of interest.

\section{REFERENCES}

1. Goussia AC, Kyritsis AP, Mitlianga P, Bruner JM. Genetic abnormalities in oligodendroglial and ependymal tumours. $J$ Neurol 2001;248:1030-5.

2. Louis DN, Ohgaki H, Wiestler OD, Cavenee WK, Burger PC, Jouvet A, Scheithauer BW, Kleihues P. The 2007 WHO classification of tumours of the central nervous system. Acta Neuropathol 2007;114:97-109. 
3. Prados MD, Berger MS, Wilson CB. Primary central nervous system tumors: advances in knowledge and treatment. CA Cancer J Clin 1998;48:331-60, 321.

4. Reni M, Brandes AA, Vavassori V, Cavallo G, Casagrande F, Vastola F, Magli A, Franzin A, Basso U, Villa E. A multicenter study of the prognosis and treatment of adult brain ependymal tumors. Cancer 2004;100:1221-9.

5. Samartzis D, Gillis CC, Shih P, O'Toole JE, Fessler RG. Intramedullary Spinal Cord Tumors: Part I-Epidemiology, Pathophysiology, and Diagnosis. Global Spine J 2015;5:425-35.

6. Alexiou GA, Tsiouris S, Kyritsis AP, Voulgaris S, Argyropoulou MI,
Fotopoulos AD. Glioma recurrence versus radiation necrosis: accuracy of current imaging modalities. JNeurooncol 2009;95:1-11.

7. Alexiou GA, Fotopoulos AD, Papadopoulos A, Kyritsis AP, Polyzoidis KS, Tsiouris S. Evaluation of brain tumor recurrence by (99m) Tc-tetrofosmin SPECT: a prospective pilot study. Ann Nucl Med 2007;21:293-8.

8. Beuthien-Baumann B, Hahn G, Winkler C, Heubner G. Differentiation between recurrent tumor and radiation necrosis in a child with anaplastic ependymoma after chemotherapy and radiation therapy. Strahlenther Onkol 2003;179:819-22. 